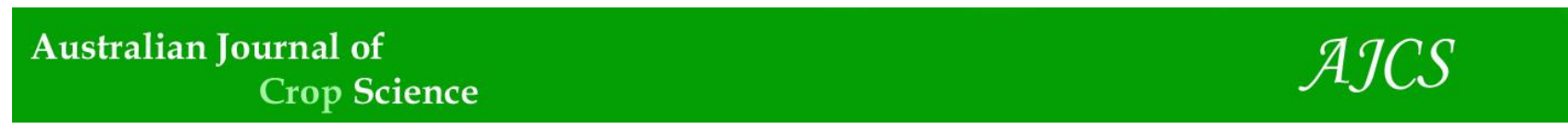

AJCS 11(12):1553-1558 (2017)

ISSN:1835-2707

doi: 10.21475/ajcs.17.11.12.pne709

\title{
Inhibitory effects of natural spices extracts on Aspergillus growth and aflatoxin synthesis
}

\author{
Fariha Ibrahim ${ }^{1}$, Muhammad Asif Asghar ${ }^{2}$, Javed Iqbal ${ }^{2.3}$, Aftab Ahmed², Abdul Basit Khan ${ }^{2 *}$ \\ ${ }^{1}$ Deparment of Microbiology, Jinnah University for Women, 5-C Nazimabad, Karachi, Pakistan \\ ${ }^{2}$ Food and Feed Safety Laboratory, Food and Marine Resources Research Centre, PCSIR Laboratories \\ Complex, Shahrah-e-Salimuzzaman Siddiqui, Off University Road, Karachi-75280, Pakistan \\ ${ }^{3}$ Pharmaceutical Manufacturing Technology Centre (PMTC), Bernal Institute, University of \\ Limerick, Castletroy, Limerick, Ireland
}

\section{*Corresponding Author: basitanalyst@gmail.com}

\begin{abstract}
Aflatoxins are naturally occurring toxic metabolites produced by many Aspergillus particularly Aspergillus flavus and Aspergillus parasiticus in food and feed products. These toxins are hepatotoxic and mutagenic causing severe health disorders including hepatitis and hepatocellular carcinoma (HCC). Various physical and chemical strategies have been introduced to control the growth and aflatoxin production. However, due to safety concerns and potent toxicity of chemicals, researchers are seeking for cost-effective and non-toxic alternates of plant origins to prevent deterioration of grain crops. The aim of this study was to check the effect of natural spices products such as aniseed, black cumin, black pepper, cardamom and turmeric extracts on the growth of pathogenic strains and their ability to produce aflatoxin contamination. Antifungal activity of spices including black cumin, turmeric, black pepper, cardamom and aniseed were performed against aflatoxigenic strain of Aspergillus parasiticus. Water soluble extracts of these spices were prepared, agar diffusion assay was performed and zone of inhibition was measured after applying different concentrations of extracts against the above strain. Subsequently, aflatoxin inhibition assay was performed by inoculating sub-inhibitory concentrations of these extracts with aflatoxigenic strain in Czapek Dox liquid medium. After incubation, thin layer chromatography (TLC) was performed to detect and quantify aflatoxins. All extracts have shown concentration dependent antifungal activity and best results were obtained with cardamom which was active even at $0.005 \%$ concentration. In addition, it was also observed that the synthesis of toxin was inhibited by all extracts and maximum activity at the concentration of $0.00025 \%$ was shown by black cumin, black pepper and aniseed. Our study showed that these extracts are effective to control aflatoxigenic strains of Aspergillus and aflatoxin contamination and may be considered as an alternative to control post-harvest fungal diseases.
\end{abstract}

Keywords: Aflatoxins; Aspergillus species; Natural extracts; Antifungal.

\section{Introduction}

Aflatoxins (AFs) are classified as the most important subgroup of mycotoxins. These toxins are carcinogenic and may cause acute and chronic outcomes including liver damage, immunological consequence and may leads to liver cancer (William et al., 2004). AFs were first identified in the early 1960s in England as the causative agent in turkey X disease that destroyed more than 100,000 turkey fowl (Khun and Ghannoum, 2003). Several types of AFs are produced, however aflatoxin $\mathrm{B}_{1}\left(\mathbf{A F B}_{1}\right), \mathrm{B}_{2}\left(\mathbf{A F B}_{2}\right), \mathrm{G}_{1}\left(\mathbf{A F G}_{1}\right)$ and $\mathrm{G}_{2}$ $\left(\mathbf{A F G}_{2}\right)$ are the four most important and naturally occurring $\mathrm{AFs} . \mathrm{AFB}_{1}$ is considered as the most common naturally occurring carcinogenic compound (IARC, 2002).

Aflatoxin contamination is a major problem that gradually turns more important due to their association in crop production, food quality and in animal and human health. The problem of AFs contamination is more serious in developing countries due to suitable climate, agricultural practices and storage conditions for the proliferation of fungus and toxin production (Aziz and Moussa, 2004). Several strategies have been established including various chemical and physical methods to prevent AFs contamination in susceptible foodstuff, plants and crops (Cleveland and Bhatnagar, 1992). Physical methods including the use of UV light, treatment with heat, and ionizing radiations are not completely useful. The application of chemical compounds has directed to several health and ecological problems due to their residual toxicity, carcinogenicity, hormonal imbalance and spermatotoxicity (Kumar et al., 2007; Pandey, 2003). To inhibit AFs biosynthesis by aflatoxigenic Aspergillus, there is a need to design novel and environmentally safe methods of reducing infection (Razzaghi-Abyaneh, 2009). Adequate control measures to prevent spoilage of grains and foodstuffs are essential to avoid contamination and decrease public health hazards. Natural plant extracts could provide an alternative to chemical preservatives. Recently, there is an increased interest to control the fungal growth and toxin production by using naturally occurring compounds.

Spices are used in the food industry to enhance flavors and fragrances. Spices and herbs are usually considered harmless and proved to be efficient against diseases (Hema et al. 2009). Moreover, they also express beneficial antimicrobial properties (Nychas and Skandamis, 2003). Medicinal and antimicrobial properties of natural extracts have been wellstudied. These extracts can provide potential alternatives to control post-harvest fungal deterioration of different crops. Several herb extracts may possibly inhibit the biosynthesis of 
AFs by controlling the growth of fungi and mycotoxin production (Steinhart et al., 1996). These compounds are safe to humans, because they have been used as a preservative, flavoring the food and for their antioxidant and medicinal properties (Hesseltine, 1965; Nakatini, 1994).

So, The aim of this study was to evaluate the antifungal activity of some natural spices extracts i.e. black cumin, turmeric, black pepper, cardamom and aniseed on the growth of Aspergillus species and $\mathrm{AF}$ production. The findings achieved during the research have been contributed to the safety assessment of food and agricultural commodities being exposed to AFs contamination.

\section{Results}

\section{Effect of spices extracts on fungal growth}

Antifungal activity of aqueous extracts of different spices was tested against aflatoxigenic A. parasiticus species, by using agar well diffusion method. A total of five (05) different aqueous spices extracts were used to evaluate their antifungal activity. Various concentrations of extracts were tested to find out the inhibitory effect by measuring zone of inhibitions. The results of all spices extracts are summarized in Table 1. The graphical data representing the zone of inhibition $(\mathrm{mm})$ of individual extracts at different concentrations are illustrated in Fig. 1 (a-e).

All extracts have shown inhibition against $A$. parasiticus at highest concentrations. The activity of each extract was concentration dependent and inhibitory effect of all extracts increased as the concentration increases. Highest percent inhibition was observed when $1 \%$ cardamom and $1 \%$ aniseed extracts were applied in wells of their respective plates (Fig. 1d, 1e). Furthermore, cardamom was showing its inhibitory effect at lowest concentration of $0.005 \%$. As far as aniseed activity was concerned, it was showing good antifungal activity at higher concentrations, but the activity was diminished at lower concentrations. Black cumin, black pepper and turmeric were consistent with their antifungal activity and their activity became zero at $0.005 \%$ concentration of extract (Fig. 1a, 1b, 1c).

\section{Effect of Spices extracts on Aflatoxin (AFs) production}

A. parasiticus was also tested to evaluate anti-aflatoxigenic activity of these spices extracts. It was grown on Czapek Dox Medium (Oxoid, UK) supplemented with different concentrations of extracts not inhibitory to fungal growth. $\mathrm{AFs}$ were extracted and analysed on TLC plates, and $\mathrm{AFB}_{1}$ and $\mathrm{AFB}_{2}$ standards were used as positive controls. $\mathrm{AFB}_{1}$ and $\mathrm{AFB}_{2}$ were completely inhibited by black cumin, black pepper and aniseed extracts at all concentrations except the lowest i.e. $0.00005 \%$. On the other hand, turmeric and cardamom had shown inhibition only at higher concentrations i.e. $0.005 \%$ and $0.0025 \%$ respectively, and its AFs inhibition activity was diminished at lower concentrations. The minimum inhibitory concentrations of all extracts against AFs synthesis are presented in Table 2.

\section{Discussion}

Fungi are commonly distributed as environmental contaminants. These fungi produce toxic compounds known as mycotoxins. Mycotoxins contaminate variety of agricultural products such as cereals, grains, spices, etc. Among several types of mycotoxins, aflatoxins (AFs) are considered to be the most important in terms of their toxicity and spectrum of activity. AFs are the secondary metabolites produced by some Aspergillus species, such as A. flavus and A. parasiticus. AFs have been considered as one of the most carcinogenic substances.

Spices and herbs have been used to enhance the flavor and aroma of food for thousands of centuries. Spices are commonly used as natural antimicrobial agents in foods. This study demonstrated the antifungal evaluation of five different aqueous spices extracts i.e. black cumin, turmeric, black pepper, cardamom and aniseed against $\mathrm{FH} 44$ A. parasiticus strain. In this study, all of the extracts have shown antifungal activity at different levels in which the best antifungal activity was observed in cardamom even at the minimum concentration of $0.005 \%$. It contains high level of phenolic contents that's why it has shown significant activity (Kapoor et al., 2008). Several studies reported that the phenolic antioxidants compounds play a significant role in antimicrobial activity of spices, it has been found to act as free radical scavengers as well as metal chelators (Shahidi and Wanasundara, 1992; Sanchez-Moreno et al., 1998). Madsen and Bertelsen have revealed that terpenoids also plays significant role in antioxidant activity of spices (1995). Furthermore, it is expected that the antifungal activity of cardamom could be due to the antagonistic or synergistic action of its components. It has also demonstrated that majority of the natural antioxidative compounds frequently work synergistically with each other to produce a broad spectrum of antioxidative actions that produces an efficient defence system against free radical attack (Vardar et al., 2003). Similar results with cardamom were observed against A. niger by Hema et al. (2009). The rest of the extracts have also shown an effective activity against fungal growth which diminished at lower concentration of extracts. Several studies have reported that the extracts of fruit and herbs possess antifungal activities against A. parasiticus (Soliman and Badeaa, 2002; Rasooli and Owlia, 2005). The antifungal activity of Nigella sativa seeds (black cumin) extract have been reported in several studies against A. parasiticus, Candida albicans and Saccharomyces cerevisiae (De et al., 1999; Khan et al., 2003). Research has also been done to explore the antifungal activity of turmeric against $A$. niger and A. flavus which showed predominant activity against these species (Arora, 1999). Furthermore, ethanolic extract of turmeric also showed inhibition against Rhizopus stolonifer and Mucor spp (Pundir and Jain, 2010). In contrast to the present study, another study has reported that the ethanolic extract of turmeric was highly effective as compared to hexane and water (Gur et al., 2006). Our findings suggest that the aqueous extract are equally effective and have shown good antifungal activity. It was observed in this study that these spices extracts are also very effective against fungal strains.

AFs contamination in many food and feed stuffs and agricultural commodities is the most important problem and may vary with environmental conditions, production and storage practices. The production of AFs is mainly influenced by physical and biological factors (Bankole and Adebanjo, 2003). The anti-aflatoxigenic activity of five (05) different aqueous spices extracts were examined for their effects on AFs production by TLC. For AFs inhibition, sub-optimal concentrations of extracts, i.e. the concentration below the inhibitory value of extracts, have been used. The extracts of black cumin, black pepper and aniseed have shown complete inhibition of $\mathrm{AFB}_{1}$ and $\mathrm{AFB}_{2}$ except the lowest, i.e. $0.00005 \%$. However, black cumin and black pepper extracts 
Table 1. Antifungal activity of spices extracts on Aspergillus parasiticus isolated from food and feed commodities.

\begin{tabular}{|c|c|c|c|c|c|c|c|c|}
\hline \multirow{2}{*}{$\begin{array}{l}\text { S. } \\
\text { No. }\end{array}$} & \multirow{2}{*}{ Extracts } & \multicolumn{7}{|c|}{ Concentration of extract (\%) } \\
\hline & & 0 (Control) & 1 & 0.5 & 0.1 & 0.05 & 0.01 & 0.005 \\
\hline \multirow[t]{3}{*}{1.} & Aniseed & & & & & & & \\
\hline & $\begin{array}{l}\text { Zone of Inhibition } \\
\text { mm. (mean } \pm \text { SD) }\end{array}$ & 0.0 & $72.6 \pm 2.05^{\mathrm{a}}$ & $62.6 \pm 3.29^{\mathrm{b}}$ & $29.3 \pm 4.92^{c}$ & 0.0 & 0.0 & 0.0 \\
\hline & $\begin{array}{l}\text { Percentage } \\
\text { Inhibition \% }\end{array}$ & 0.0 & 80.7 & 69.6 & 32.6 & 0.0 & 0.0 & 0.0 \\
\hline \multirow[t]{3}{*}{2.} & Black Cumin & & & & & & & \\
\hline & $\begin{array}{l}\text { Zone of Inhibition } \\
\mathrm{mm} .(\text { mean } \pm \text { SD) }\end{array}$ & 0.0 & $46.3 \pm 5.50^{\mathrm{a}}$ & $31.0 \pm 6.55^{\mathrm{b}}$ & $29.0 \pm 3.60^{\mathrm{b}}$ & $27.0 \pm 3.60^{\mathrm{b}}$ & $19.3 \pm 4.04^{\mathrm{c}}$ & 0.0 \\
\hline & $\begin{array}{l}\text { Percentage } \\
\text { Inhibition \% }\end{array}$ & 0.0 & 51.5 & 34.5 & 32.3 & 30.0 & 21.5 & 0.0 \\
\hline \multirow[t]{3}{*}{3.} & Black Pepper & & & & & & & \\
\hline & $\begin{array}{l}\text { Zone of Inhibition } \\
\text { mm. }(\text { mean } \pm \text { SD) }\end{array}$ & 0.0 & $47.3 \pm 2.05^{\mathrm{a}}$ & $40.0 \pm 4.08^{\mathrm{b}}$ & $31.0 \pm 2.94^{\mathrm{c}}$ & $30.3 \pm 3.68^{c}$ & $24.3 \pm 4.18^{\mathrm{d}}$ & 0.0 \\
\hline & $\begin{array}{l}\text { Percentage } \\
\text { Inhibition \% }\end{array}$ & 0.0 & 52.6 & 44.5 & 34.5 & 33.7 & 27.0 & 0.0 \\
\hline \multirow[t]{3}{*}{4.} & Cardamom & & & & & & & \\
\hline & $\begin{array}{l}\text { Zone of Inhibition } \\
\text { mm. }(\text { mean } \pm \text { SD) }\end{array}$ & 0.0 & $74.3 \pm 7.58^{\mathrm{a}}$ & $64.6 \pm 1.69^{\mathrm{b}}$ & $60.3 \pm 3.68^{\mathrm{b}}$ & $49.6 \pm 0.45^{\mathrm{c}}$ & $25.7 \pm 1.53^{\mathrm{d}}$ & $17.0 \pm 1.73^{\mathrm{e}}$ \\
\hline & $\begin{array}{l}\text { Percentage } \\
\text { Inhibition \% }\end{array}$ & 0.0 & 82.6 & 71.8 & 67.0 & 55.2 & 28.5 & 18.8 \\
\hline \multirow[t]{3}{*}{5.} & Turmeric & & & & & & & \\
\hline & $\begin{array}{l}\text { Zone of Inhibition } \\
\text { mm. }(\text { mean } \pm \text { SD) }\end{array}$ & 0.0 & $64.0 \pm 2.97^{\mathrm{a}}$ & $51.6 \pm 4.98^{\mathrm{b}}$ & $47.3 \pm 2.05^{\mathrm{b}}$ & $34.0 \pm 4.32^{\mathrm{c}}$ & $25.7 \pm 4.04^{\mathrm{d}}$ & 0.0 \\
\hline & $\begin{array}{l}\text { Percentage } \\
\text { Inhibition \% }\end{array}$ & 0.0 & 71.2 & 57.4 & 52.6 & 37.8 & 28.5 & 0.0 \\
\hline
\end{tabular}

Any two means not sharing a letter in a row differ significantly at $\mathrm{P}<0.05$ (LSD) (n=3)
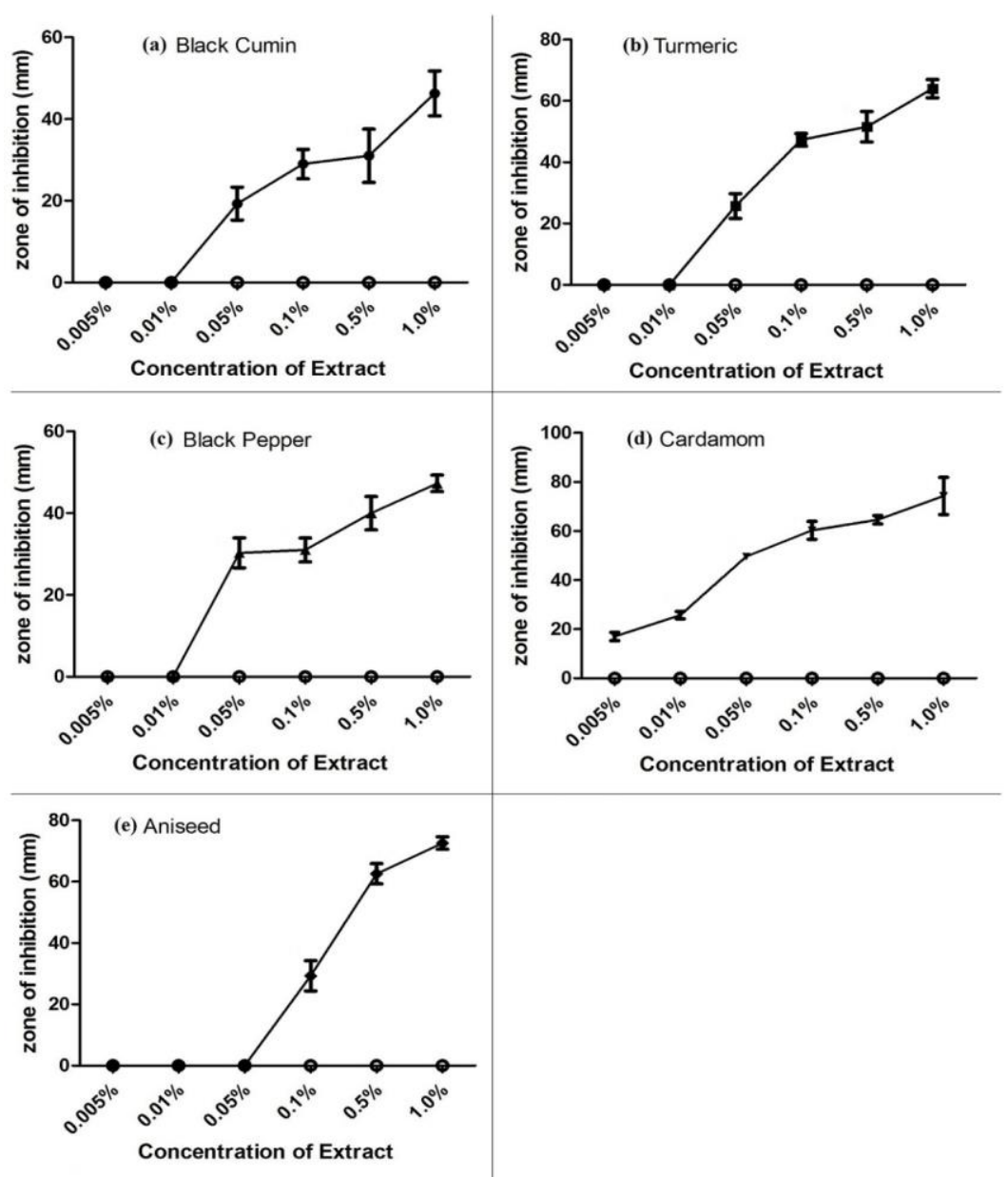

Fig 1. Antifungal activity of a) Black cumin, b) Turmeric, c) Black pepper, d) Cardamom, and e) Aniseed against Aflatoxigenic Aspergillus parasiticus on PDA after 07 days of incubation. Different concentrations of extracts were applied and zone of inhibition was measured after incubation. 
Table 2. Anti-aflatoxigenic activity of spices extracts on Aspergillus parasiticus isolated from food and feed commodities.

\begin{tabular}{|c|c|c|c|c|c|c|c|}
\hline \multirow[t]{2}{*}{ S.No. } & \multirow[t]{2}{*}{ Extracts } & \multicolumn{6}{|c|}{ Concentration of extract (\%) } \\
\hline & & 0 (Control) & 0.005 & 0.0025 & 0.0005 & 0.00025 & 0.00005 \\
\hline \multirow[t]{3}{*}{1.} & Aniseed & & & & & & \\
\hline & Aflatoxin $\mathrm{B}_{1}$ & + & ND & ND & ND & ND & + \\
\hline & $\begin{array}{l}\text { Aflatoxin } \mathrm{B}_{2} \\
\text { Black Cumin }\end{array}$ & + & ND & ND & ND & ND & + \\
\hline 2. & Aflatoxin $\mathrm{B}_{1}$ & + & ND & ND & ND & ND & + \\
\hline \multirow[t]{2}{*}{3.} & $\begin{array}{l}\text { Aflatoxin } \mathrm{B}_{2} \\
\text { Black Pepper }\end{array}$ & + & ND & ND & ND & ND & + \\
\hline & Aflatoxin $\mathrm{B}_{1}$ & + & ND & ND & ND & ND & + \\
\hline \multirow[t]{2}{*}{4.} & $\begin{array}{c}\text { Aflatoxin } \mathrm{B}_{2} \\
\text { Cardamom }\end{array}$ & + & ND & ND & ND & ND & + \\
\hline & Aflatoxin $\mathrm{B}_{1}$ & + & NT & ND & + & + & + \\
\hline \multirow[t]{3}{*}{5.} & $\begin{array}{c}\text { Aflatoxin } \mathrm{B}_{2} \\
\text { Turmeric }\end{array}$ & + & NT & ND & + & + & + \\
\hline & Aflatoxin $\mathrm{B}_{1}$ & + & ND & + & + & + & + \\
\hline & Aflatoxin $\mathrm{B}_{2}$ & + & ND & + & + & + & + \\
\hline
\end{tabular}

(ND = Toxin Not Detected, $+=$ Toxin Detected, NT $=$ Not Tested $)$

have shown moderate antifungal activity, but they have potential to inhibit the production of AFs. As far as the aniseed activity was concerned it has shown good antifungal activity only at higher concentrations but they have inhibited the AFs production at all concentrations. On the other hand, turmeric and cardamom had shown inhibition only at higher concentrations i.e. $0.005 \%$ and $0.0025 \%$ respectively, and its AFs inhibition activity was diminished at lower concentrations. Although, turmeric and cardamom have shown good antifungal activity, they are not able to inhibit the AFs production in lower concentrations. It might be possible that these extracts do not target the synthesis machinery of the cell and only damage the structural components of an organism result in growth inhibition. Similarly, turmeric leaf oil showed toxin inhibition at $1.0 \%$ and $1.5 \%$ (Sindhu et al., 2011). The level of AFs inhibition and fungal growth was dependent on the essential oil concentration. It has been shown that the essential oils mainly target the cell membrane and cell wall (Nazzaro et al., 2013). In case of thyme essential oil at $250 \mathrm{ppm}$, the plasma membrane of $A$. parasiticus, was seen to be irregular and invaginated. Such variations might be related to the interference of essential oil components with enzymatic reactions of cell wall synthesis, which influences fungal morphogenesis and growth (Abdolamir et al., 2011).

\section{Materials and Methods}

\section{Fungal strain}

Several food and feed samples were screened, as reported earlier, for the presence of aflatoxigenic Aspergillus strains (Ibrahim et al., 2016). Aspergillus parasiticus (FH44) was selected for the experiment on the basis of its toxicity. This strain has shown the highest amount of AFs when isolated from a sample of maize (Ibrahim et al., 2016). Inoculum was prepared according to the method described by Ghadeer and Al-Delamiy (2012). Briefly, the growth of Aspergillus species in a petri plate was washed with $10 \mathrm{ml}$ sterile distilled water, 10 -fold serial dilutions were made and spore numbers were adjusted to $10^{5}$ spores $/ \mathrm{ml}$.

\section{Extraction of spices}

Several raw spices products were used to check the effects of these products on aflatoxigenic A. parasiticus species. These include: black cumin (Nigella sativa), turmeric (Curcuma longa), black pepper (Piper nigrum), cardamom (Elettaria cardamomum) and aniseed (Pimpinella anisum). These spices were purchased from local market in Karachi-Pakistan. Spices were washed with deionized water and dried in oven at $50^{\circ} \mathrm{C}$ for 24 hours. Dried spices were kept in a plastic bag until further use.

Hot water extraction was performed to separate water soluble extracts of spices. Spices products were grinded separately and $10 \mathrm{~g}$ of each was added in $100 \mathrm{ml}$ of distilled water. Boiling was done for 1 hour and supernatant was separated after filtration/centrifugation. The extracts were concentrated through rotary evaporator and dried in oven at $75-80^{\circ} \mathrm{C}$. One gram of each extract was weighed and dissolved in $10 \mathrm{ml}$ of sterile distilled water and it was further serially diluted in sterile distilled water and several dilutions, i.e. $1 \%, 0.5,0.1,0.05,0.01$ and $0.005 \%$ were prepared to determine the minimum inhibitory concentration. The left over dried extracts were preserved in a sterile vial for future use.

\section{Antifungal Activity}

Agar well diffusion method: Agar well diffusion method was performed as reported earlier by Pundir and Jain with slight modification (2010). Potato dextrose agar (Oxoid-UK) was autoclaved and spore suspension $\left(10^{5} / \mathrm{ml}\right)$ was added into the molten medium. Culture Medium was poured into sterile petri plates and allowed to solidify, followed by the formation of $10 \mathrm{~mm}$ size diameter wells with sterile borer. One hundred micro litre of the different concentration of spices extract were added in their respective wells and incubated at $25 \pm 2{ }^{\circ} \mathrm{C}$ for $5-7$ days. Sterilized distilled water was used as a negative control and acetic acid (SigmaAldrich, USA) was used as a positive control which was introduced into the well instead of spices extract. All combinations were tested on duplicate plates and all experiments were performed in triplicate. After incubation, plates were observed for any zone of inhibition surrounding the wells containing the spices extract. The zone of inhibition was measured; mean and standard deviation of the diameter were calculated. Furthermore, percent inhibition was calculated as described by Singh and Tripathi using the following equation (1999);

$$
\text { Inhibition }(\%)=\frac{\mathrm{dc}-\mathrm{dt}}{\mathrm{Dc}} \times 100
$$


Where, $d_{c}$ is the average diameter of mycelia colony of control and $d_{t}$ is the average diameter of treated plate with extract.

Aflatoxin inhibition assay: The efficiency of spices extracts to reduce AFs production were evaluated by the method stated by Zohra and Fawzia (2013). Czapek Dox liquid medium (Oxoid, UK) was prepared, supplemented with different concentrations of extracts separately, followed by the inoculation of fungal spore suspension $\left(10^{5}\right.$ spores $\left./ \mathrm{ml}\right)$. Sub-inhibitory concentration i.e., concentrations of each spices extracts below inhibitory concentration were used to evaluate their effect on AFs production. Positive control was also prepared, contained only spore suspension, the flasks were incubated at $25 \pm 2^{\circ} \mathrm{C}$ for 10 days.

After incubation, thin layer chromatography (TLC) was performed as described earlier for detection and quantification of AFs (Asghar et al., 2014). Dried extracts were suspended in $100 \mathrm{ml}$ of benzene (Merck, Germany):acetonitrile (Merck, Germany) (98:2; v/v) and shake well. Samples were spotted as 2,5 and $10 \mu l$ and standards were separately applied on the TLC plates on imagining line about $4 \mathrm{~cm}$ from bottom edge. The plates were developed in unlined tank containing $20 \mathrm{ml}$ of chloroform (Merck, Germany): xylene (Merck, Germany): acetone (Merck, Germany) $(6: 3: 1 ; \mathrm{v} / \mathrm{v})$ and was observed under long wavelength UV light $(\lambda=254$ and $366 \mathrm{~nm})$ in UV visualizer. The retention factor (Rf) of each AFs $\left(B_{1}, B_{2}, G_{1}\right.$ or $\left.G_{2}\right)$ was calculated according to the following equation.

$$
\text { Rf }=\frac{\text { Distance moved by compound }}{\text { Distance moved by solvent }}
$$

Furthermore, all positive results of AFs, naturally existing in the tested samples, were confirmed by spraying the TLC plates using $50 \%(\mathrm{v} / \mathrm{v}) \mathrm{H}_{2} \mathrm{SO}_{4}$ (Sigma-Aldrich, USA). All combinations were tested in duplicate and all experiments were repeated three times.

\section{Statistical analysis}

As mentioned earlier, all experiments were performed in triplicate. Mean and standard deviation was calculated and treatment results of antifungal activity were statistically evaluated using one-way ANOVA through Graphpad Prism5 software. Mean separation test was done using least significance difference (LSD) (Steel et al. 1997).

\section{Conclusion}

It is widely accepted that the use of artificial chemicals to control postharvest diseases has been limited due to their carcinogenicity, teratogenicity, long degradation period, environmental pollution and their adverse effects on food and human health. Moreover, Inactivation of AFs through physical and chemical means has not yet proved to be effective and economically feasible (Mishra and Das, 2003). Instead of chemicals, natural spices extracts may provide an alternative to protect foods or feeds from fungal contamination and AFs production. Our study endorses the idea that these spices extracts will most likely to be the best to use as food additives in different food industries to prevent contamination and deterioration by aflatoxigenic Aspergillus strains.

\section{Acknowledgment}

The authors are thankful to Dr. Omer Mukhtar Tarar, senior scientific officer in PCSIR laboratories, Karachi for his valuable input in statistical analysis. We are also grateful to the management of PCSIR laboratories, Karachi and Department of Microbiology, Jinnah University for Women, Karachi for providing all resources for this work.

\section{References}

Abdolamir A, Tahereh Z, Iraj R (2011) Phytoinhibition of growth and aflatoxin biosynthesis. In: Dr Irineo TorresPacheco (ed) Toxigenic fungi, aflatoxins-detection, measurement and control. Retrieved January 20, 2015 from Intech website.

http://www.intechopen.com/books/aflatoxinsdetectionmeasurement-and-control/phytoinhibition-of-growth-andaflatoxin-biosynthesis-in-toxigenic-fungi.

Arora DS (1999) Some Indian spices and their antimicrobial properties. In: Singh $\mathbf{J}$ and Aneja KR (eds) From ethnomycology to fungal biotechnology: Exploiting fungi from natural resources for novel products. Kluwer Academic/Plenum Publishers, New York.

Asghar MA, Iqbal J, Ahmed A, Khan MA (2014) Occurrence of aflatoxins contamination in brown rice from Pakistan. Iran J Public Health. 43:291-299.

Aziz NH, Moussa LA (2004) Reduction of fungi and mycotoxins formation in seeds by gamma-radiation. J Food Safety. 24:109-127.

Bankole SA, Adebanjo A (2003) Mycotoxins in food in West Africa: current situations and possibilities for controlling it. Afr J Biotechnol. 2:254-263.

Cleveland TE, Bhatnagar D (1992) Molecular strategies for reducing aflatoxin levels in crops before harvest. In: Bhatnagar D, Cleveland TE (eds) Molecular Approaches to Improving Food Quality and Safety. Van Nostrand Reinhold, New York.

De M, De AK, Banerjee AB (1999) Antimicrobial screening of some Indian Spices. Phytother Res. 13:616-618.

Ghadeer AO, Al-Delamiy KS (2012) Aflatoxin B1 production by Aspergillus flavus in different media and containers and the antifungal activity of garlic and black cumin. Res J Eng Appl Sci. 1:117-121.

Gur SD, Balik T, Gur N (2006) Antimicrobial activity and some fatty acids of turmeric, ginger root and linseed used in the treatment infectious disease. World J Agric Sci. 2:439-442.

Hema R, Kumaravel S, Elanchezhiyan N (2009) Antimicrobial activity of some of the South-Indian spices and herbals against food pathogens. Global J Pharmcol. 3:38-40.

Hesseltine CW (1965) A millennium of fungi, food and fermentation. Mycologia. 57: 149-197.

Ibrahim F, Jalal H, Khan AB, Asghar MA, Iqbal J, Ahmed A, Nadeem G (2016) Prevalence of aflatoxigenic Aspergillus in food and feed samples from Karachi, Pakistan. J Infect Mol Biol. 4:1-8.

IARC working group (2002) Some Mycotoxins. In: Monograph on the evaluation of carcinogenic risk to humans. International agency for research in cancer (IARC), World Helath Organiztion (WHO). Vol. 82. IARC press, Lyon, France.

Kapoor IPS, Singh B, Singh G, Isidorov V, Szczepaniak L (2008) Chemistry, antifungal and antioxidant activities of cardamom (Amomum subulatum) essential oil and oleoresins. Int J Essent Oil Therap. 2:29-40. 
Khan MAU, Ashfaq MK, Zuberi HS, Mahmood MS, Gilani $\mathrm{AH}$ (2003) The in vivo antifungal activity of the aqueous extract from Nigella sativa seeds. Phytother Res. 17:183186.

Kuhn DM, Ghannoum MA (2003) Indoor mold, toxigenic fungi, and Stachybotrys chartarum: infectious disease perspective. Clin Microbiol Rev. 16:144-172.

Kumar R, Mishra AK, Dubey NK, Tripathi YB (2007) Evaluation of Chenopodium ambrosioides oil as a potential source of antifungal, antiaflatoxigenic and antioxidant activity. Int J Food Microbiol. 115:159-164.

Madsen HL, Bertelsen G (1995) Spices as antioxidants. Trends Food Sci Technol. 6:271-277.

Mishra HN, Das C (2003) A review on biological control and metabolism of aflatoxin. Crit Rev Food Sci Nutr. 43:245264.

Nakatini N (1994) Antioxidative and antimicrobial constituents of herbs and spices. In: Herbs and edible fungi, pp. 251-284, Elsevier Science, Amsterdam.

Nazzaro F, Fratianni F, De Martino L, Coppola R, De Feo V (2013) Effect of essential oils on pathogenic bacteria. Pharmaceuticals (Basel). 6:1451-1474.

Nychas GJE, Skandamis PN (2003) Antimicrobials from herbs and spices. In: Roller S (ed) Natural antimicrobials for the minimal processing of foods. 1st edn. Woodhead publishing limited and CRC press LLC, New York.

Pandey R (2003) Pesticide and sterility. Everyman's Science. 38:84-86.

Pundir RK, Jain P (2010) Comparative studies on the antimicrobial activity of black pepper (Piper nigrum) and turmeric (Curcuma longa) extracts. Int J Appl Biol Pharm Technol. 1:491-501.

Rasooli I, Owlia P (2005) Chemoprevention by thyme oils of Aspergillus parasiticus growth and aflatoxin production. Phytochemistry. 66:2852-2856.

Razzaghi-Abyaneh M, Shams-Ghahfarokhi M, Rezaee MB, Jaimand K, Alinezhad S, Saberi R, Yoshinari T (2009) Chemical composition and antiaflatoxigenic activity of
Carum carvi L., Thymus vulgaris and Citrus aurantifolia essential oils. Food Control. 20:1018-1024.

Sanchez-Moreno C, Larrauri JA, Saura-Calixto F (1998) A procedure to measure the anti-radical efficiency of polyphenols. J Sci Food Agric. 76:270-276.

Shahidi F, Wanasundara PKJPD (1992) Phenolic antioxidants: Crit Rev Food Sci Nutr. 32:67-103.

Sindhu S, Chempakam B, Leela NK, Suseela R (2011) Chemoprevention by essential oil of turmeric leaves (Curcuma longa L.) on the growth of Aspergillus flavus and aflatoxin production. Food Chem Toxicol. 49:11881192.

Singh J, Tripathi NN (1999) Inhibition of storage fungi of black gram (Vigna mungo) by some essential oils. Flavour Frag J. 14:1-4.

Soliman KM, Badeaa RI (2002) Effect of oil extracted from some medicinal plants on different mycotoxigenic fungi. Food Chem Toxicol. 40:1669-1675.

Steel RGD, Torrie JH, Dickey DA (1997) Principles and procedures of statistics: A biometrical approach. McGraw Hill Book Co. Inc., New York.

Steinhart CE, Doyle ME, Cochrane BA (1996) A food safety. In: Steinhart CE and Cochrane BA (eds) Mycotoxins. Marcel Dekker, New York.

Vardar Unlu G, Candan F, Sokmen A, Daferera D, Polissiou M, Sokmen M, Domez E, Tepe B (2003) Antimicrobial and antioxidant activity of the essential oil and methanol extracts of Thymus pectinatus Fisch. et Mey. var. pectinatus (Lamiaceae). J Agric Food Chem. 51:63-7.

William J, Philips TD, Jolly PE, Stiles JK, Jolly CM, Agarwal D (2004) Human aflatoxicoses in developing countries: a review of toxicology exposure, potential health consequences and interventions. Am J Clin Nutr. 80:11061122.

Zohra M, Fawzia A (2013) Fungitoxic effect of natural extracts on mycelial growth, spore germination and aflatoxin B1 production of Aspergillus flavus. Aust J Crop Sci. 7:293-298. 